\title{
Erratum to: Advances in Human Factors in Simulation and Modeling
}

\author{
Daniel N. Cassenti
}

\author{
Erratum to: \\ D. N. Cassenti (Ed.): \\ Advances in Human Factors in Simulation and Modeling, \\ AISC 780, https://doi.org/10.1007/978-3-319-94223-0
}

The original version of the book was inadvertently published with incorrect Figs. 3a and $3 \mathrm{~b}$ in chapter "Classification Algorithms in Adaptive Systems for NeuroErgonomic Applications", which have to be now corrected and an acknowledgment section has to be newly included in chapter "Approaches to Study Spine Biomechanics: A Literature Review". The erratum book has been updated with the changes.

The updated online version of these chapters can be found at https://doi.org/10.1007/978-3-319-94223-0_39

https://doi.org/10.1007/978-3-319-94223-0_43

(C) Springer Nature Switzerland AG 2019

D. N. Cassenti (Ed.): AHFE 2018, AISC 780, p. E1, 2019.

https://doi.org/10.1007/978-3-319-94223-0_50 